Pacific Journal of Mathematics

CONVERGENCE OF INVERSE SYSTEMS 


\section{CONVERGENCE OF INVERSE SYSTEMS}

\section{JACK SEgAL}

1. Introduction. Let $X_{i}$ be a metrizable continuum for each positive integer $i$, and let $f_{i}$ be a mapping of $X_{i+1}$ onto $X_{i}$. Let $X$ be the inverse limit space of the inverse system $\left(\left\{X_{i}\right\},\left\{f_{i}\right\}\right)$; in notation $X=\lim \left(\left\{X_{i}\right\},\left\{f_{i}\right\}\right)$, and let $\pi_{i}$ be the projection mapping of $X$ onto $X_{i}$. In [2] it is proved that if metrics $d_{i}$ for $X_{i}$ are properly chosen then the inverse limit space $X=\lim \left(\left\{X_{i}\right\},\left\{f_{i}\right\}\right)$ is locally connected if and only if the collection $\left\{\left(X_{i}, d_{i}\right) \mid i\right.$ a positive integer $\}$ of metric spaces is equi-uniformly locally connected. Also the $X_{i}$ were embedded in their cartesian product in such a way that $X$ is locally conndected if and only if the sequence $X_{1}, X_{2}, X_{3}, \cdots$ converges 0 -regularly to $X$.

In this paper similar relations between semi-local connectedness, equi-uniform semi-local connectedness and 0-coregular convergence are established. These results are then combined with known results about 0 -regular and 0-coregular convergence to obtain properties of certain inverse limit spaces. For example, if each $X_{i}$ is a simple closed curve and $X$ is semi-locally connected and cyclic, (i.e., without cut points), then $X$ is a simple closed curve. Similar theorms for 2-spheres and 2-cells are also obtained.

For definitions and results on semi-local connectedness see [5] or [6], equi-uniform local connectedness [2], inverse limits [1], 0-regular and O-coregular convergence [3] and [4]. Throughout this paper $S_{\varepsilon}(p)$ will denote $\varepsilon$-neighborhood of $p$.

REMARK 1. Note the following relationship for the case where $X$ is cyclic between semi-local connectedness and local connectedness:

If $X$ is cyclic then it is $\left\{\begin{array}{l}\text { locally connected } \\ \text { semi-locally connected }\end{array}\right\}$ at a point $p$ if and only if for each $\varepsilon>0$ there exists a $\delta>0$ such that any two points $\left\{\begin{array}{l}\text { inside } S_{\delta}(p) \\ \text { outside } S_{\varepsilon}(P)\end{array}\right\}$ can be joined by a connected set lying $\left\{\begin{array}{l}\text { inside } S_{\varepsilon}(p) \\ \text { outside } S_{\delta}(p)\end{array}\right\}$. Note also that since $X$ is compact it is locally connected (semi-locally connected) if and only if it is uniformly locally connected (uniformly semi-locally connected).

\section{Equi-uniform semi-local connectedness.}

Definition 1. A collection $\left\{\left(Y_{\alpha}, \rho_{\alpha}\right) \mid \alpha \in A\right\}$ of metric spaces is equiuniformly locally connected if and only if corresponding to each $\varepsilon>0$

Received January 23, 1961. 
there is a $\delta>0$ such that if $\alpha \in A$ and $s$ and $t$ are members of $Y_{\alpha}$ for which $\rho_{\alpha}(s, t)<\delta$ then $s$ and $t$ lie in a connected subset of $Y_{\alpha}$ of diameter less than $\varepsilon$.

Definition 2. A collection $\left\{\left(Y_{\alpha}, \rho_{\alpha}\right) \mid \alpha \in A\right\}$ of metric spaces is equiuniformly semi-locally connected if and only if corresponding to each $\varepsilon>0$ there is a $\delta>0$ such that if $\alpha \in A$ then for any $p$ in $Y_{\alpha}$ and $s$ and $t$ in $Y_{\alpha}-S_{\varepsilon}(p)$ we have $s$ and $t$ lie in a connected subset of $Y_{\alpha}-S_{\delta}(p)$.

DEFINITION 3. Let $d_{i}$ be a metric for $X_{i}$ for each positive integer $i$. The sequence $d_{1}, d_{2}, d_{3}, \cdots$ is admissible if there exists a metric $d$ for $X$ such that

$$
\lim _{i \rightarrow \infty} d_{i}\left(\pi_{i}(u), \pi_{i}(v)\right)=d(u, v)
$$

uniformly on $X \times X$.

REMARK 2. Let $D_{i}$ be a metric for $X_{i}$ such that $D_{i}(x, y) \leqq 1$ for all $x$ and $y$ in $X_{i}$. If $i>j$ let $f_{i j}$ denote the composite mapping $f_{j} \cdots f_{i-2} f_{i-1}$.

Define

$$
d_{i}(x, y)=\sum_{j=1}^{i} 2^{-\jmath} D_{j}\left(f_{\imath j}(x), f_{i j}(y)\right)
$$

for each positive integer $i$ and all $x$ and $y$ in $X_{i}$. Also define

$$
d(u, v)=\sum_{j=1}^{\infty} 2^{-j} D_{j}\left(\pi_{j}(u), \pi_{j}(v)\right) .
$$

In ([7], Theorem 1) it is shown that $\lim _{1-\infty} d_{i}\left(\pi_{i}(u), \pi_{i}(v)\right)=d(u, v)$ uniformly on $X \times X$ and hence the sequence $d_{1}, d_{2} \cdots$ is admissible.

THEOREM 1. Suppose $d_{i}$ is a metric for $X_{i}$ for each $i$ and the sequence $d_{1}, d_{2}, d_{3}, \cdots$ is admissible. Then if $X$ is cyclic it is semilocally connected if and only if the collection $\left\{\left(X_{i}, d_{i}\right) \mid i \geqq n\right\}$ is equi-uniformly semi-locally connected for some positive integer $n$.

Proof. Suppose $\left\{\left(X_{i}, d_{i}\right) \mid i \geqq n\right\}$ is equi-uniformly semi-locally connected. For any $\varepsilon>0$, there exists a $\delta>0$ such that for any $p$ in $X_{i}$ and $x$ and $y$ in $X_{i}-S_{\varepsilon / 3}(p)$ we have $x$ and $y$ are contained in a connected subset of $X_{i}-S_{\delta}(p)$. Now suppose $u$ and $v$ are in $X-S_{\varepsilon / 3}(q)$ where $\pi_{i}(q)=p$. There exists a positive integer $m$ such that if $i \geqq m$ then $\pi_{i}(u)$ and $\pi_{i}(v)$ are in $X_{i}-S_{\varepsilon / 3}(p)$. For $i \geqq \max (m, n)$ let $K_{i}$ be a connected subset of $X_{i}-S_{\delta}(p)$ containing $\pi_{i}(u)$ and $\pi_{i}(v)$. Let $H_{i}$ denote the closure of $\bigcup_{j \geq i} f_{j i}\left[K_{j}\right]$. Each $H_{i}$ is a continuum, $f_{j i}\left[H_{j}\right] \subset H_{i}$ for $j>i$, so $\left.H=\lim \left(\left\{H_{i}\right\},\left\{f_{i} \mid H_{i+1}\right)\right\}\right)$ is a subcontinuum of $X-S_{\delta}(q)$ containing $u$ and $v$. Hence since $X$ is cyclic it is semi-locally connected. 
Now assume $X$ is semi-locally connected and cyclic. Suppose $\varepsilon>0$. Then there exists a $\delta^{*}>0$ such that for any $p$ in $X$ if $u$ and $v$ are in $X-S_{\varepsilon / 2}(p)$ they lie in a connected subset of $X-S_{\delta / 2}(p)$. There is a positive integer $n$ such that if $i \geqq n$ and $u$ and $v$ are in $X$ then $\left|d_{i}\left(\pi_{i}(u), \pi_{i}(v)\right)-d(u, v)\right|<\min \left(\delta^{*} / 6, \varepsilon / 2\right)$. Now suppose $i \geqq n$ and $x$ and $y$ are in $X_{i}$ for which $x$ and $y$ are in $X_{i}-S_{\varepsilon}\left(p_{i}\right)$ where $\pi_{i}(p)=p_{i}$. There exists $u$ and $v$ in $X$ such that $\pi_{i}(u)=x$ and $\pi_{i}(v)=y$. It follows $u$ and $v$ are in $X-S_{\varepsilon / 2}(p)$ and hence $u$ and $v$ lie in a connected subset $K$ of $X-S_{\delta^{*} / 2}(p)$. Since $\operatorname{diam}\left(\pi_{1}^{-1}\left(p_{i}\right)\right)<\delta^{*} / 6$ we have $K \cap \pi_{i}^{-1}\left(p_{i}\right)=\phi$. Therefore $\pi_{i}(K)$ is a connected subset of $X_{i}$ which contains $x$ and $y$ and is contained in $X_{i}-S_{\delta^{*} / 3}\left(p_{i}\right)$. Let $\delta=\delta^{*} / 3$. Then the collection $\left\{\left(X_{i}, d_{i}\right) \mid i \geqq n\right\}$ is equi-uniformly semi-locally connected.

3. O-coregular convergence. Let $P$ be the cartesian product of the sequence $X_{1}, X_{2}, \cdots$. Let $D_{i}, d_{i}$ and $d$ be metrics defined as in Remark 2. If we define a metric $d^{*}$ for $P$ by

$$
d^{*}(a, b)=\sum_{i=1}^{\infty} 2^{-j} D_{j}\left(a_{j}, b_{j}\right) \text { for } a=\left(a_{1}, a_{2}, \cdots\right) \text { and } b=\left(b_{1}, b_{2}, \cdots\right),
$$

then the inclusion map is an isometry of $(X, d)$ into $\left(P, d^{*}\right)$. Choose a point $p=\left(p_{1}, p_{2}, \cdots\right)$ in $P$, and define for each positive integer $i$ an isometry $h_{i}$ on $\left(X_{i}, d_{i}\right)$ into $\left(P, d^{*}\right)$ by letting

$$
h_{i}(x)=\left(f_{i 1}(x), \cdots, f_{i i}(x), p_{i+1}, p_{i+2}, \cdots\right)
$$

where $f_{i i}$ is the identity map. In the following denote $h_{i}\left[X_{i}\right]$ by $X_{i}^{*}$.

THEOREM 2. The sequence $X_{1}^{*}, X_{2}^{*}, \cdots$ converges 0-coregularly to $X$ if and only if $X$ is semi-locally connected and cyclic.

Proof. It is obvious that $X_{1}^{*}, X_{2}^{*}, \cdots$ converges to $X$. Suppose $X$ is semi-locally connected and cyclic, then it follows from Theorem 1 that the collection $\left\{\left(X_{i}, d_{i}\right) \mid i \geqq n\right\}$ of metric spaces is equi-uniformly semi-locally connected for some positive integer $n$. Since each $h_{i}$ is an isometry, it follows at once that $X_{1}^{*}, X_{2}^{*}, \cdots$ must converge 0 -coregularly to $X$.

Now suppose the sequence $X_{1}^{*}, X_{2}^{*}, \cdots$ converges 0 -coregularly to $X$. Then by ([4], Theorem 2.1) $X$ must be semi-locally connected and cyclic. White proved the following lemma in [4].

Lemma 1. If $A_{i} \rightarrow A$ 0-coregularly and if each $A_{i}$ is a $\left\{\begin{array}{l}\text { simple closed curve } \\ \text { 2-sphere and } A_{i} \rightarrow A \text { 0-regularly } \\ \text { 2-cell and } A_{i} \rightarrow A \text { 0-regularly }\end{array}\right\}$

then $A$ is a (simple closed curve or a point) 2-sphere or a point

2-cell, 2-sphere or a point 
THEOREM 3. If $X$ is semi-locally connected and cyclic and each $X_{1}$ is a simple closed curve, then $X$ is a simple closed curve.

Proof. Since $X$ is semi-locally connected and cyclic, by Theorem 2 $X_{i}^{*} \rightarrow X 0$-coregularly where $X_{i}^{*}$ is isometric to $X_{i}$. So by Lemma $1 X$ is a simple closed curve.

Lemma 2. ([2], Theorem 3) The sequence $X_{1}^{*}, X_{2}^{*}, \cdots$ converges 0 -regularly to $X$ if and only if $X$ is locally connected.

THEOREM 4. If $X$ is locally connected and cyclic and each $X_{6}$ is a 2-sphere then $X$ is a 2-sphere.

Proof. For compact spaces local connectedness implies semi-local connectedness. So $X$ is semi-locally connected and cyclic. Therefore by Theorem $2 X_{i}^{*} \rightarrow X$ 0-coregularly and by Lemma $2 X_{i}^{*} \rightarrow X$ 0-regularly where $X_{i}^{*}$ is isometric to $X_{i}$. So by Lemma $1, X$ is a 2-sphere or a point and since $\pi_{i}$ maps $X$ onto $X_{i}$, we have $X$ is a 2 -sphere.

THEOREM 5. If $X$ is locally connected and cyclic and each $X_{\imath}$ is a 2-cell then $X$ is a 2-cell.

Proof. Since $X$ is locally connected and cyclic $X_{\imath}^{*} \rightarrow X 0$-coregularly and by Lemma $2 X_{i}^{*} \rightarrow X 0$-regularly where $X_{i}^{*}$ is isometric to $X_{i}$. So by Lemma $1 X$ is a 2-cell, 2 -sphere or a point. The third possibility is ruled out since $\pi_{i}$ maps $X$ onto $X_{i}$. Since the second Čech homology group of each $X_{i}$ is zero so is that of $X$. Hence the second possibility is ruled out also. So $X$ is a 2-cell.

REMark 3. To see the need for requiring $X$ to be cyclic in Theorem 5 consider Example 1 of [2]. Each $X_{i}$ is a 2-cell but $X$ is an arc. So since $X$ is locally connected $X_{i}^{*} \rightarrow X$-regularly but not 0 -coregularly since $X$ has a cut point.

\section{BIBLIOGRAPHY}

1. C. E. Capel, Inverse limit spaces, Duke Math. J., 26 (1954), 233-245,

2. M. K. Fort and J. Segal, Local connectedness of inverse limit spaces, Duke Math. J., 28 (1961), 253-260.

3. P. A. White, Regular convergence, Bull. Amer. Math. Soc., 60 (1954), 431-443.

4. - New types of regular convergence, Duke Math. J., 12 (1945), 305-315.

5. G. T. Whyburn, Semi-locally connected sets, Amer. J. of Math., 61 (1939), 733-749.

6. - Analytic Topology, Amer. Math. Soc. Colloquium Publications, Vol. 28, 1942.

ThE UNIVERSITY OF WASHINGTON 


\section{PACIFIC JOURNAL OF MATHEMATICS}

\section{EDITORS}

Ralph S. Phillips

Stanford University

Stanford, California

M. G. Arsove

University of Washington

Seattle 5, Washington
A. L. Whiteman

University of Southern Californla

Los Angeles 7, California

Lowell J. Paige

University of California

Los Angeles 24, California

\section{ASSOCIATE EDITORS}

E. F. BECKENBACH

D. DERRY

H. L. ROYDEN

E. G. STRAUS

T. M. CHERRY

M. OHTSUKA

E. SPANIER

F. WOLF

\section{SUPPORTING INSTITUTIONS}

UNIVERSITY OF BRITISH COLUMBIA

STANFORD UNIVERSITY

CALIFORNIA INSTITUTE OF TECHNOLOGY

UNIVERSITY OF CALIFORNIA

MONTANA STATE UNIVERSITY

UNIVERSITY OF TOKYO

UNIVERSITY OF UTAH

UNIVERSITY OF NEVADA

NEW MEXICO STATE UNIVERSITY

OREGON STATE UNIVERSITY

UNIVERSITY OF OREGON

OSAKA UNIVERSITY

WASHINGTON STATE UNIVERSITY

UNIVERSITY OF WASHINGTON

UNIVERSITY OF SOUTHERN CALIFORNIA

AMERICAN MATHEMATICAL SOCIETY CALIFORNIA RESEARCH CORPORATION SPACE TECHNOLOGY LABORATORIES NAVAL ORDNANCE TEST STATION 


\section{Pacific Journal of Mathematics}

\section{Vol. 12, No. $1 \quad$ January, 1962}

Jonathan L. Alperin, Groups with finitely many automorphisms $\ldots \ldots \ldots \ldots \ldots \ldots \ldots \ldots$

Martin Arthur Arkowitz, The generalized Whitehead product ................ 7

John D. Baum, Instability and asymptoticity in toplogical dynamics . . . . . . . . . . 25

William Aaron Beyer, Hausdorff dimension of level sets of some Rademacher series .... $\quad 35$

Frank Herbert Brownell, III, A note on Cook's wave-matrix theorem . . . . . . . . . . . . . 47

Gulbank D. Chakerian, An inequality for closed space curves ................. 53

Inge Futtrup Christensen, Some further extensions of a theorem of Marcinkiewicz ....... 59

Charles Vernon Coffman, Linear differential equations on cones in Banach spaces . . . . . 69

Eckford Cohen, Arithmetical notes. III. Certain equally distributed sets of integers . . . . . 77

John Irving Derr and Angus E. Taylor, Operators of meromorphic type with multiple poles

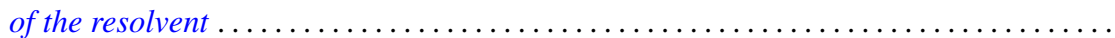

Jacob Feldman, On measurability of stochastic processes in products space .............

Robert S. Freeman, Closed extensions of the Laplace operator determined by a general class of boundary conditions, for unbounded regions ......................

Robert E. Fullerton, Geometric structure of absolute basis systems in a linear topological

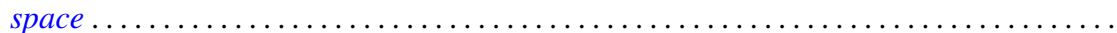

Dieter Gaier, On conformal mapping of nearly circular regions

Andrew Mattei Gleason and Hassler Whitney, The extension of linear functionals defined

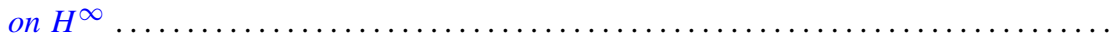

Seymour Goldberg, Closed linear operators and associated continuous linear

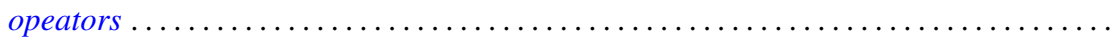

Basil Gordon, Aviezri Siegmund Fraenkel and Ernst Gabor Straus, On the determination of sets by the sets of sums of a certain order

Branko Grünbaum, The dimension of intersections of convex sets. .

Paul Daniel Hill, On the number of pure subgroups

Robert Peter Holten, Generalized Goursat problem . .

Alfred Horn, Eigenvalues of sums of Hermitian matrices ...........

Henry C. Howard, Oscillation and nonoscillation criteria for

$$
y^{\prime \prime}(x)+f(y(x)) p(x)=0
$$

Taqdir Husain, $S$-spaces and the open mapping theorem ...

Richard Eugene Isaac, Markov processes and unique stationary probability measures ...

John Rolfe Isbell, Supercomplete spaces ....................

John Rolfe Isbell, On finite-dimensional uniform spaces. II .........

N. Jacobson, A note on automorphisms of Lie algebras ..............

Antoni A. Kosinski, A theorem on families of acyclic sets and its applications

Marvin David Marcus and H. Minc, The invariance of symmetric functions of singular values...

Ralph David McWilliams, A note on weak sequential convergence.

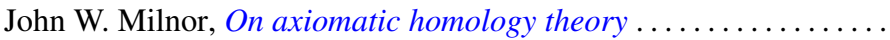

Victor Julius Mizel and Malempati Madhusudana Rao, Nonsymmetric projections in

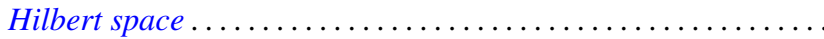

Calvin Cooper Moore, On the Frobenius reciprocity theorem for locally compact

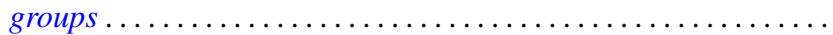

Donald J. Newman, The Gibbs phenomenon for Hausdorff means . 